\title{
Persistent Right Umbilical Vein in Trisomy 18: Sonographic Observation
}

\author{
Luc De Catte, MD, Kaan Osmanagaoglu, MD, Inge De Schrijver, MS
}

Persistent right umbilical vein is a rare entity, with a prevalence of about $0.22 \% .^{1}$ The intrahepatic variant is observed most frequently, and $72 \%$ of the fetuses are normal.2,3 In a very limited number of cases, the persistent right umbilical vein terminates directly into the right atrium, without passage into the liver. The majority of fetuses with this variety have multiple congenital malformations. ${ }^{2}$

We report a case of persistent right umbilical vein draining directly into the right atrium in association with trisomy 18. Although particular sonographic markers related to Edwards syndrome were present in our case, we would recommend fetal karyotyping in all cases of persistent right umbilical vein.

\footnotetext{
Received June 8, 1998, from the Department of Feto-Maternal Medicine, University Hospital Brussels, Brussels, Belgium. Revised manuscript accepted for publication September 13, 1998.

Address correspondence and reprint requests to Luc De Catte, MD, Department of Feto-Maternal Medicine, University Hospital Brussels, Laarbeeklaan 101, 1090 Brussels, Belgium.
}

\section{CASE REPORT}

A 35 year old Turkish woman had had three uncomplicated pregnancies and deliveries. A fourth pregnancy ended in an unexplained fetal death at 6 months' gestation. The parents refused postmortem investigation. The woman's medical history was unremarkable. A routine second trimester ultrasonographic examination at 22 weeks of gestation showed a normal fetal biometry for gestational age, mild polyhydramnios, and the presence of a single umbilical artery. In addition, a choroid plexus cyst measuring $7 \times 15 \mathrm{~mm}$ was observed in the left ventricle, and both ears were low set. The fetus had rocker bottom feet, and both hands were clenched. The lower lobes of the right lung were echogenic. The gallbladder was enlarged and had an abnormal transverse position close to the anterior abdominal wall (Fig. 1). The umbilical vein did not connect with portal circulation in the liver but coursed over the anterior abdominal wall through the anterior portion of the diaphragm directly into the right atrium (Figs. $2,3)$. The ventricular outflow tracts were normal, and venous return in the right atrium by the inferior and superior venae cavae was intact. The diagnosis of persistent right umbilical vein draining directly into the right atrium in a fetus showing characteristics of trisomy 18 was made. Fetal blood sampling for fast karyotyping confirmed the presence of a female trisomy 18 fetus in all examined metaphases. Termination of pregnancy was performed.

Gross pathologic examination clearly revealed the presence of the clenched hands and the rocker bottom feet. The fetal abdomen was slightly distended; right and left liver lobes were of equal size. The enlarged gallbladder was 


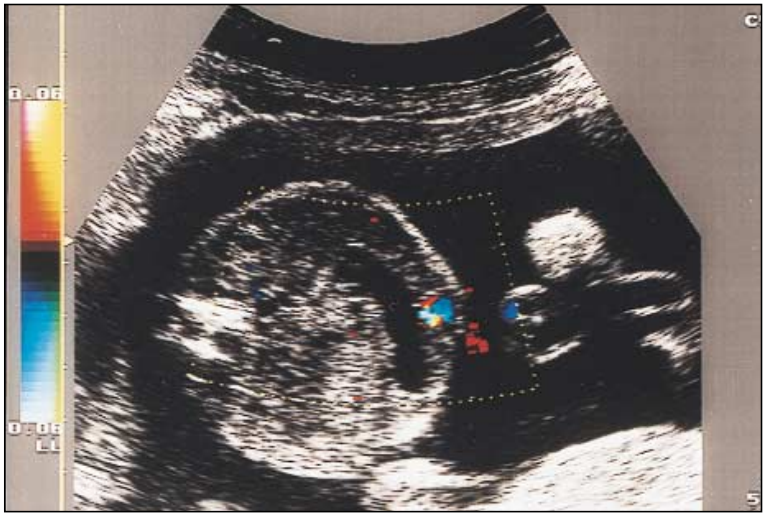

Figure 1 Transverse section at the level of the fetal liver shows the transversely oriented and enlarged gallbladder.

draped over the inferior surface of the liver from left to right. A small craniocaudal groove on the anterior surface of the liver guided the umbilical vein from its entrance at the umbilicus directly into the right atrium. No other vascular abnormalities were observed. Intestinal malrotation also was present.

\section{DISCUSSION}

Obliteration and disappearance of the right umbilical vein starts in the fourth week of embryonic development.2,4 The initial connection of both umbilical veins with the sinus venosus is lost when the umbilical veins anastomose with the hepatic sinusoids. Failure of this process results in the direct connection of both umbilical veins to the right atrium. The growth of the fetal liver then causes kinking of the right umbilical vein, subsequent occlusion, and regression. However, on rare occasions and for yet unknown reasons the left umbilical vein becomes obliterated. Since normal flow in the liver was already established, the ductus venosus does form, but the blood flow in the liver is abnormal.

The prevalence of persistent right umbilical vein, estimated through targeted prenatal fetal sonographic examinations, is now at 2.2 per 1000 births; this is not as rare as previously believed.1,3,4 Persistent right umbilical vein is diagnosed sonographically on the transverse fetal section obtained to measure the abdominal circumference. 4 Normally, the left umbilical vein passes at the left side of the gallbladder and connects with the portal vein. It then curves right, away from the stomach. In the intrahepatic form of persistent right umbilical vein, the

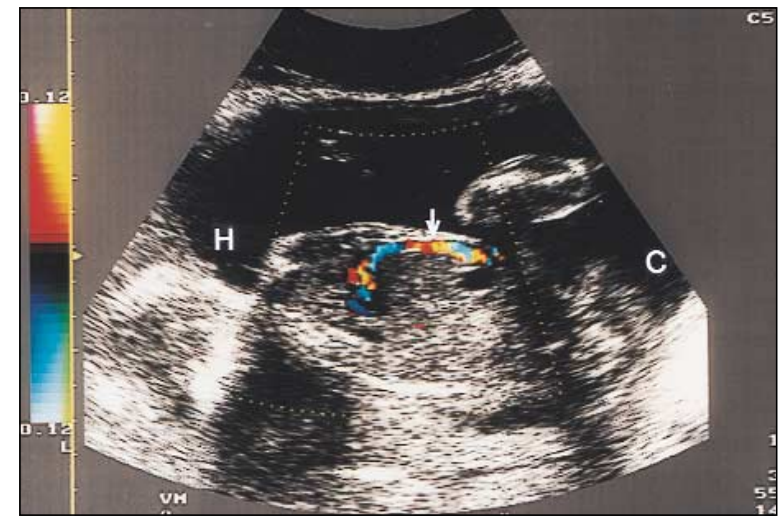

Figure 2 Longitudinal scan of the fetal abdomen reveals the course of the right umbilical vein (arrow) from the umbilicus to the heart, anterior to the liver. $\mathrm{C}$, Fetal caudal end; $\mathrm{H}$, fetal cranial end.

umbilical vein passes lateral and to the right side of the gallbladder, fuses with the left portal vein, and then bends toward the stomach. Whenever the right umbilical vein does not connect with the portal system but enters the right atrium directly, as in our case, or enters the superior vena cava, the vein runs anteriorly over the liver. This form of persistent right umbilical vein has rarely been diagnosed prenatally. Color Doppler sonography facilitates the identification of the abnormal vessels and their course in cases of poor image resolution. ${ }^{4-6}$

The spectrum of sonographic, clinical, and autopsy findings in trisomy 18 syndrome has been reported extensively.7,8 In the present case, typical sonographic markers for trisomy 18 were noted: mild polyhydramnios, choroid plexus cyst, clenched

Figure 3 Transverse section of the fetal thorax at the level of the four-chamber view shows the entrance of the right umbilical vein $(\mathrm{u})$ directly into the right atrium (a).

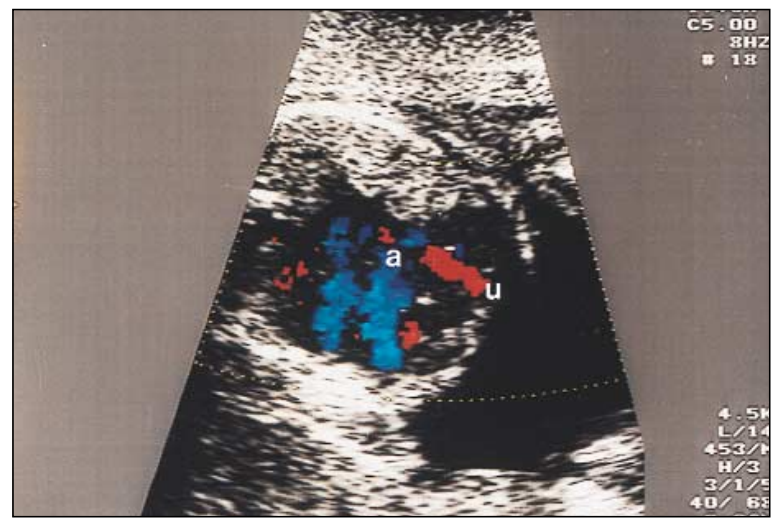


hands, and rocker bottom feet. Although at least 30 different cardiovascular malformations have been described in trisomy 18, a persistent right umbilical vein draining directly into the right atrium had not been observed previously.

Persistent right umbilical vein has been associated with a large variety of anomalies related to the intestinal, cardiovascular, urogenital, and skeletal systems, as reported by Shen and coworkers. ${ }^{1}$ In the absence of malformations, isolated persistent right umbilical vein probably is of little significance to pregnancy outcome.1,3 Of the 74 fetuses (Table 1) with intrahepatic persistent right umbilical vein reported in the literature, $53(72 \%)$ were normal. In eight of the 74 fetuses more than one organ system was involved; two of these were diagnosed as representing Noonan syndrome. Severe central nervous system lesions have been reported in four cases, and cardiovascular malformations were found in six fetuses. ${ }^{1-6,9-13}$ Although Jeanty has reported the initial survival rate as low as 33\%,4 recent compilations of cases show a better prognosis.2,6

All but one of the published cases $(n=8)$ of persistent right umbilical vein connecting to the superior vena cava or the right atrium manifested at least one malformation commonly encountered in the Edwards syndrome ${ }^{2,10,12,14-16}$ (Table 2). The absence of one umbilical artery was the most consistent finding

Table 1: Intrahepatic Persistent Right Umbilical Vein and Associated Malformations

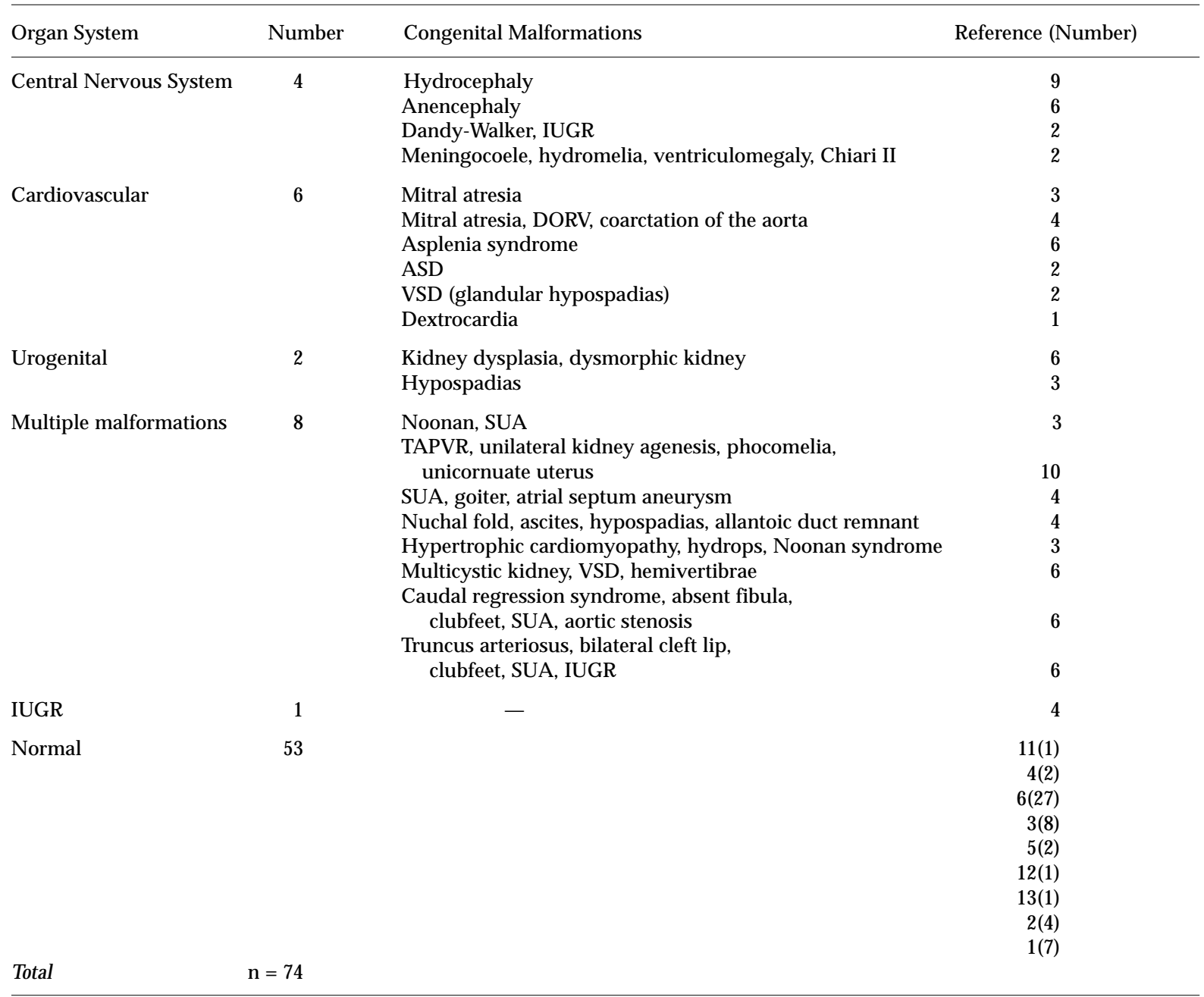

IUGR, Intrauterine growth restriction; DORV, double outlet right ventricle; ASD, atrial septal defect; VSD, ventricular septal defect; SUA, single umbilical artery; TAPVR, Total anomalous pulmonary venous return. 
Table 2: Persistent Right Umbilical Vein Draining into the Right Atrium: Associated Malformations and Outcome

\begin{tabular}{|c|c|c|c|}
\hline Reference & Associated Malformations & Outcome & Prenatal Diagnosis \\
\hline 14 & SUA & Stillbirth & - \\
\hline 10 & $\begin{array}{l}\text { SUA, esophageal atresia, tracheoesophageal } \\
\text { fistula; annular pancreas; duodenal atresia; } \\
\text { imperforate anus; accessory spleens }\end{array}$ & Full term pregnancy & - \\
\hline 10 & $\begin{array}{l}\text { SUA; situs inversus of the viscera; bilateral } \\
\text { hydronephrosis; sirenomelia }\end{array}$ & Preterm delivery at 35 weeks & - \\
\hline 10 & $\begin{array}{l}\text { SUA; exstrophy of the heart, liver, spleen, } \\
\text { stomach; tetralogy of Fallot }\end{array}$ & Preterm delivery 8 months & - \\
\hline 15 & $\begin{array}{l}\text { SUA; right-sided cardiac apex; intestinal } \\
\text { malrotation; left-sided liver }\end{array}$ & Full term pregnancy & - \\
\hline 12 & None & Full term pregnancy & + \\
\hline 16 & $\begin{array}{l}\text { SUA; agenesis of the right kidney; interruption } \\
\text { of the intrahepatic inferior vena cava with } \\
\text { hemiazygos continuation; bifid right thumb; } \\
\text { hemivertebra }\end{array}$ & Delivery at 39 weeks & + \\
\hline 2 & $\begin{array}{l}\text { SUA; right hydronephrosis; hypertelorism; } \\
\text { syndactyly; hemivertebra }\end{array}$ & Not available & + \\
\hline
\end{tabular}

SUA, Single umbilical artery.

in this group (seven of eight), and this finding was also present in our case. Although gastrointestinal, kidney, and skeletal malformations were present in several cases, no uniform pattern was recognized. The structural defects in our case reflected two different pathologic entities: those associated with the persistence and abnormal course of the right umbilical vein (enlarged symmetric liver, transverse position of the gallbladder) and those recognized as part of a trisomy 18 syndrome (choroid plexus cyst, clenched hands, rocker bottom feet, and polyhydramnios). Because in the past fetal or neonatal karyotyping in relation to persistent right umbilical vein had not been performed systematically, chromosomal abnormalities might have been underestimated. ${ }^{6}$

We report a case of persistent right umbilical vein with a chromosomal abnormality. The finding of an abnormal vascular connection of the umbilical vein to the fetal venous circulation in association with structural defects in multiple organ systems merits chromosomal analysis. Further study is needed to clarify any relationship of persistent right umbilical vein and chromosomal defects or to deem this observation purely incidental.

\section{REFERENCES}

1. Shen O, Tadmor OP, Yagel S: Prenatal diagnosis of persistent right umbilical vein. Ultrasound Obstet Gynecol 8:31, 1996

2. Kinare AS, Ambardekar ST, Bhattacharya D, et al: Prenatal diagnosis with ultrasound of anomalous course of the umbilical vein and its relationship to fetal outcome. J Clin Ultrasound 24:333, 1996

3. Kirsch CFE, Feldstein VA, Goldstein RB, et al: Persistent intrahepatic right umbilical vein: A prenatal sonographic series without significant anomalies. J Ultrasound Med 15:371, 1996

4. Jeanty P: Persistent right umbilical vein: An ominous prenatal finding? Radiology 177:735, 1990

5. Yashuhide A, Toshiyuki H, Atsushi M, et al: Antenatal diagnosis of persistent right umbilical vein. J Clin Ultrasound 23:324, 1995

6. Hill LM, Mills A, Peterson C, et al: Persistent right umbilical vein: Sonographic detection and subsequent neonatal outcome. Obstet Gynecol 84:923, 1994

7. Gilbert-Barnes E: Chromosomal abnormalities. In Gilbert-Barnes E (Ed): Potter's Pathology of the Fetus and the Infant. St. Louis, Mosby-Year Book, 1997, p 402

8. Snijders RJM, Nicolaides KH (Ed): Ultrasound Markers for Chromosomal Defects. London, Parthenon Publishing Group, 1996

9. Fliegel $\mathrm{CP}, \mathrm{Nars}$ PW: Aberrant umbilical vein. Pediatr Radiol 14:55, 1984 
10. Bell AD, Gerlis LM, Variend S: Persistent right umbilical vein: Case report and review of literature. Int J Cardiol 10:167, 1986

11. Ricklan DE, Collett TA, Lyness SK: Umbilical vein variations: Review of the literature and a case report of a persistent right umbilical vein. Teratology 37:95, 1988

12. Jouk PS, Champetier J: Abnormal direct entry of the umbilical vein into the right atrium: Antenatal detection, embryologic aspects. Surg Radiol Anat 13:59, 1991

13. Moore L, Toi A, Chitayat D: Abnormalities of the intraabdominal fetal umbilical vein: Reports of four cases and a review of the literature. Ultrasound Obstet Gynecol 7:21, 1996
14. Monie IW: Umbilical vein entering the right atrium: Comments on a previously reported human case. Teratology 4: 461, 1971

15. Theander G, Karlsson S: Persistent right umbilical vein. Acta Radiol 19:268, 1978

16. Greiss HB, McGahan JP: Umbilical vein entering the right atrium: Significance of in utero diagnosis. J Ultrasound Med 11:111, 1992 